\title{
Industry Research into Dam and Levee Breach Erosion Through Coarser Grained Materials
}

\author{
Mark Morris ${ }^{1}$, Jean-Robert Courivaud ${ }^{2}$, Rafael Moran ${ }^{3}$, Miguel Á. Toledo ${ }^{3}$ and Christophe Picault ${ }^{4}$ \\ ${ }^{1}$ HR Wallingford (HRW), Howbery Park, Wallingford, Oxfordshire OX108BA, United Kingdom \\ ${ }^{2}$ Electricité de France (EDF), France \\ ${ }^{3}$ Universidad Politécnica de Madrid (UPM), Spain \\ ${ }^{4}$ Compangnie Nationale du Rhône (CNR), France
}

\begin{abstract}
Predicting breach erosion processes is essential for the effective risk management of both dams and levees. In recent years, a variety of research efforts have improved our knowledge of erosion processes, and in particular validation of the work on headcut erosion through cohesive soils performed at USDA-HERU. A similar level of analysis and validation is required for coarser grained and mixed materials to provide a clearer overview of when breach erosion processes change from headcut through surface erosion to slumping of rockfill. This paper presents an update on progress with a programme of research being implemented by EDF which investigates (i) how macro erosion processes change in relation to soil type and state, (ii) the validity of soil erosion relationships used for coarser and mixed grained erosion and (iii) the performance of breach models in predicting the breaching processes through an integrated programme of large-scale field and medium-scale laboratory tests.
\end{abstract}

\section{Introduction}

Predicting breach erosion processes is essential for the effective flood risk management of both dams and levees. However, the complexities and uncertainties in predicting breach processes are often not understood or ignored by using simplified approaches. The errors and uncertainties within those predictions are then buried within the subsequent use of the breach data, such as for flood inundation mapping or risk mapping.

There are multiple ways in which errors can be introduced into breach prediction, including use of overly simplified approaches, uncertainty about the rate of soil erosion (i.e. the soil erodibility) and use of inappropriate modelling approaches (e.g. using user defined breach openings, when to use headcut or surface erosion models etc.).

The objective of this programme of research is to improve knowledge regarding breaching and erosion processes, and to update 'industry available' breach model(s) with this functionality. This applies here to the erosion breach behaviour of coarser grained materials, since earlier work on headcut erosion through cohesive materials (Hanson et al (2001); Bureau of Reclamation (2017)) is considered to have validated the modelling approach for those conditions. Whilst asset managers like to consider that their dams and levees are typically constructed from erosion resistant materials (such as clays) it is often found not to be the case - particularly with older dam and levee constructions.

Hence the overall goal here is to achieve a common level of understand and prediction of breach processes across a range of soil types from cohesive to coarser sand and gravel materials, taking into consideration how different gradings affect these processes, and ultimately to provide industry with appropriate modelling tools to predict and assess risks arising from these processes.

\section{Specific goals and structure of the research programme}

Over the past decades there have been many research efforts looking at breach erosion processes, however these are often focussed on specific soil types and load conditions. Whilst the conclusions drawn are often proposed as generic solutions for predicting breach formation, the reality is that erosion behaviour and driving factors for breach vary in relation to soil type and state, and load conditions (Morris et al, 2008).

a Corresponding author: author@e-mail.org

DOI 10.3311/FLOODRisk2020.17.14 
As such, we need to first understand this 'bigger picture' as to how these processes can vary before analysing the 'jig-saw puzzle' of technical processes occurring under each of the types of behaviour. In this way we can then develop more reliable breach models which not only better represent the detailed erosion processes that occur, but which guide the user through use of appropriate macro erosion processes - such as choosing between headcut, surface erosion etc. Figure 1 shows examples of different macro erosion processes.

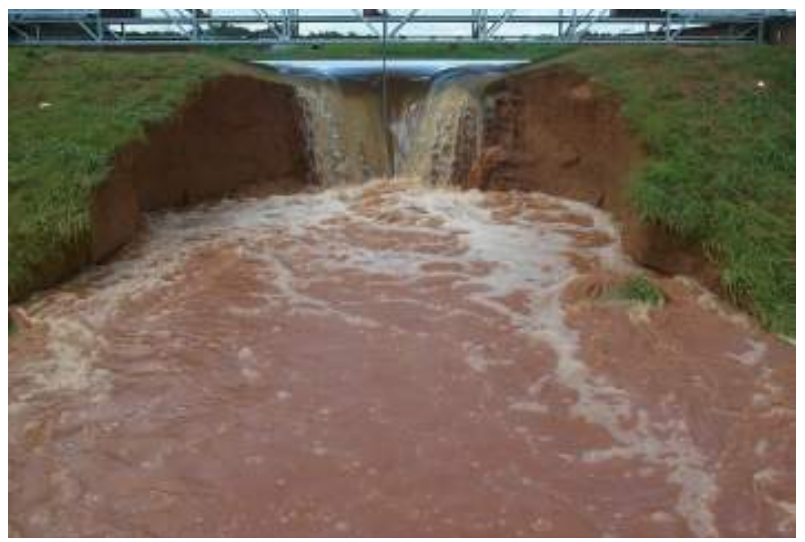

(a) Headcut erosion through a test levee [Photo: USDA-ARS-HERU Stillwater, OK. US]

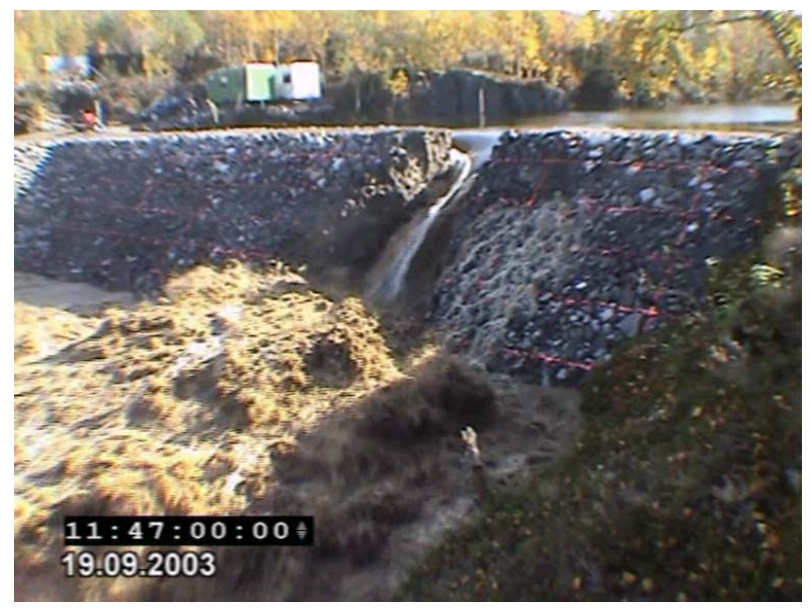

(b) Surface erosion through a test levee [Photo: EC IMPACT project]

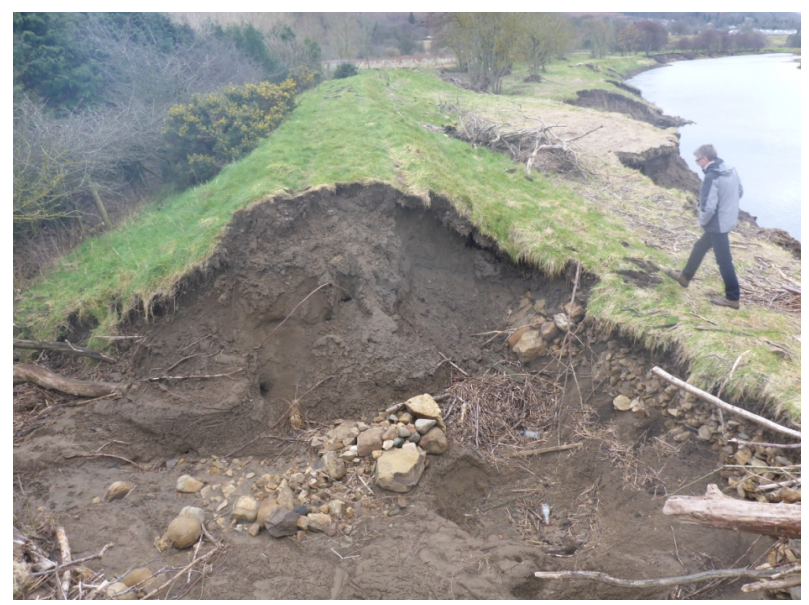

(c) Surface erosion profile through breached earth river levee (UK) [Photo: Royal Haskoning DHV]

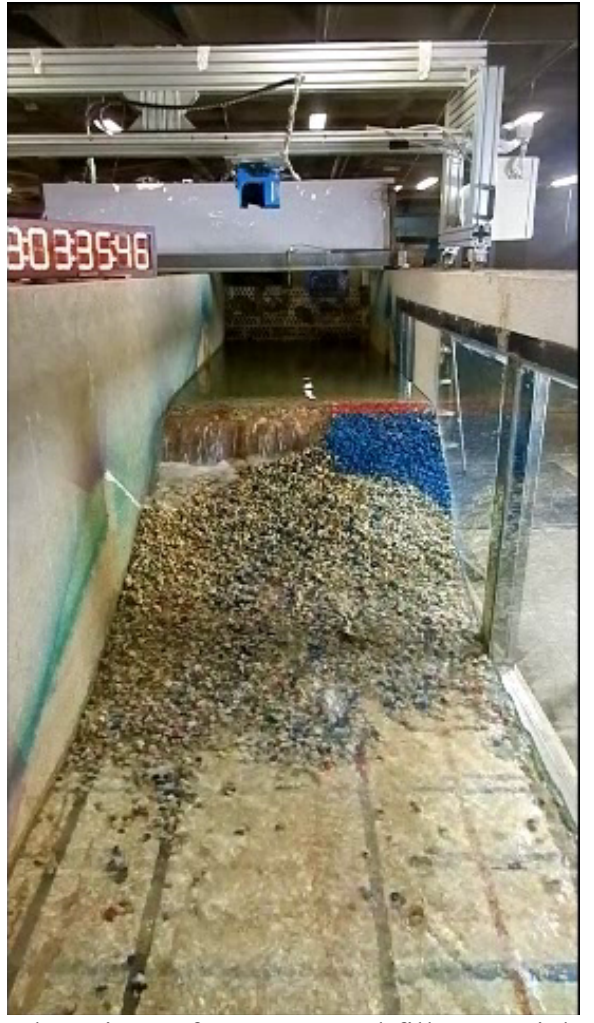

(d) Slumping of coarse rockfill material [Photo: Universidad Politécnica de Madrid, Spain]

Figure 1. Examples of different macro breach erosion processes

Since the flow through a breach is typically controlled by the upstream invert level of the eroding dam or levee section, the macro erosion process becomes important in determining when and how breach flow starts to accelerate. A purely headcut process will allow erosion of the headcut to erode a large proportion of the dam or levee body before affecting the flow control section. However, once erosion cuts through that upstream face of the dam or levee, breach formation and release of significant flow volume is rapid. On the contrary, with surface erosion, the surface of the dam or levee - including the crest - is progressively eroded, leading to a steady increase in breach discharge from the outset.

A programme of research was developed with the intention of:

(i) Confirming macro erosion processes and boundaries

(ii) Investigating micro erosion process relationships

(iii) Updating industry usable breach models with new knowledge

The approach taken was to run parallel programmes of research integrating medium-scale laboratory tests with the construction of use of a larger scale field test facility, combined with analysis and numerical modelling of the lab and field test data. With other researchers investigating soil erosion behaviour (particularly USBR, USACE and USDA in the USA, and the Hedgwich Polder Living Lab polder experiments in The Netherlands) the intention was to collaborate, align and share data wherever possible. 


\section{Progress with the laboratory programme}

The objectives, description of the experimental facility, and preliminary results of the initial tests of the laboratory program are presented in the following sections.

\subsection{Objectives of the laboratory test programme}

The objective of the test programme is to understand how breach erosion occurs in relation to the soil grading and associated parameters such as fines content, permeability etc. Since permeability affects the ingress of water in relation to surface flow, the magnitude of overflow and rate of change in overflow are also factors of interest.

A range of tests is foreseen to try and establish different 'zones' of erosion behaviour. Different soil gradings will be used - both clean and mixed - to investigate different phenomenon. The initial intent is to use clean or mixes of materials readily available at the UPM lab, which can also be replicated in the field test facility using locally sourced material. The initial materials comprise the so-called Gravel 2-8mm, Gravel 0-4mm, and Sand (Figure 2).

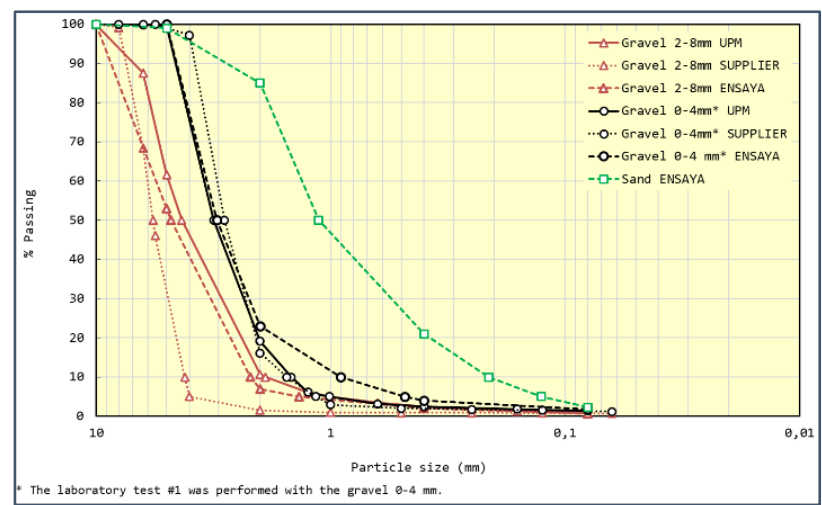

Figure 2. Soil gradings of the coarse materials for lab tests

These source materials allow for the creation of different gradings which reflect real levee material found in both Europe and the US. Figure 3 shows a series of gradings for comparison as follows:

- Example range of gradings for silty gravel levee material (EDF)

- $\quad$ Example range of gradings for gravel levee material (EDF)

- Example range of levee materials from the US (USACE ERDC)

- Example range of material gradings used for recent US soil erosion research (USACE ERDC, USBR)

- $\quad$ Grading for Overcome Project Test\#1

It is noticeable that the Test\#1 grading shows a clean material rather than graded soil. This was intended for the first few tests. Subsequent test(s) will use finer clean material and subsequently mixed material gradings.

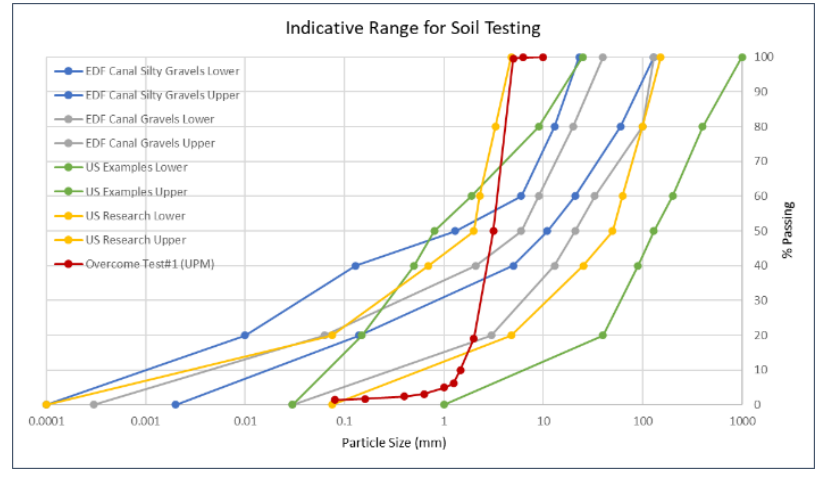

Figure 3. Soil gradings from real levees versus test programme gradings

For each test, evolution of the geometry of the breach and classification of the failure process (i.e., headcut erosion, surface erosion, or slumping) will be analysed. It is expected that later larger scale field tests will build upon the knowledge gained from this programme of laboratory tests in order to confirm key processes at larger / prototype scale.

\subsection{Flume setup and instrumentation}

The tests are being carried out in a flume facility at the Hydraulic Lab of the ETSI Caminos, Canales y Puertos of Universidad Politécnica de Madrid (UPM). The surface of the lab is $1200 \mathrm{~m}^{2}$ and has a water recirculation circuit supplied from a $270 \mathrm{~m}^{3}$ main reservoir that is located below the floor of the lab. Recirculation is achieved by 3 submersible pumps with flow discharges up to $2001 / \mathrm{s}$. The flume is $13.45 \mathrm{~m}$ long, $2.50 \mathrm{~m}$ wide, with $1.30 \mathrm{~m}$ high sidewalls.

The tests are carried out using the laboratory facilities in Level Mode, i.e., supplying water to the channel from a tank equipped to maintain a constant water level. Flow from the tank is via a $200 \mathrm{~mm}$ diameter steel pipe. The flow is controlled by a butterfly valve which can be operated either manually or by a motor drive. The measurement of flow is registered by the following devices:

- Electromagnetic flowmeter also located in the tank outlet pipe.

- Venturi located in the tank outlet pipe.

- Butterfly valve (through an opening-discharge calibration).

- Triangular/rectangular thin-plate weir located in the recirculation channel after the flume outlet.

The water surface elevation is registered by ultrasonic sensors (Figure 4) with digital recording at 30 samples per second for each sensor:

- $\quad L S \_1$. Water level downstream (at the thin-plate weir)

- $\quad L S \_2$. Water level upstream the sample

- $\quad L S 3$ (lower), LS 4, LS_5 and LS_6 (upper). Water level at the downstream slope of the granular sample.

All sensors are placed quasi-perpendicular to the free surface of the water to obtain the highest accuracy in the readings. The data registration is continuous over time 
with the specified frequency through computer data acquisition.

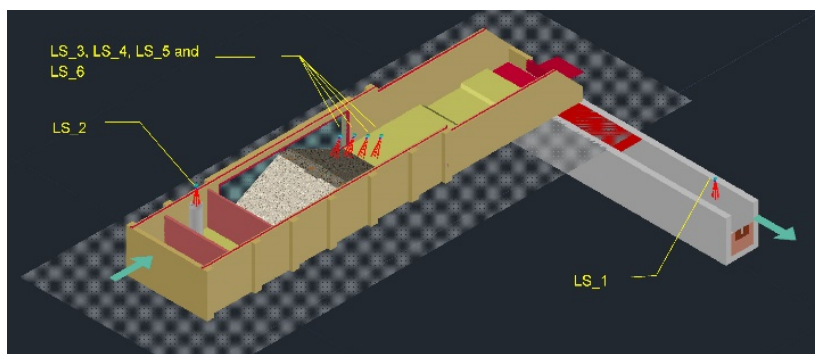

Figure 4. Scheme with the location in the flume of the ultrasonic sensors

An existing flume piezometry system is used to monitor evolution of pressures at the base of the test section. This system consists of 84 points (holes) in the channel base hydraulically connected with a system of hoses to a measurement panel located outside of the channel. The recording of these pressures is manual, but continuously recorded by video camera. The 84 pressure control points are distributed following 7 lines parallel to the flume walls, with 12 measurement points in each line. The 7 lines are arranged at offsets of $0.250,0.750$ and $1,195 \mathrm{~m}$ on each side of the central longitudinal axis of the flume.

Evolution of the external surface of the levee is registered through a laser profile device and a set of cameras positioned to allow the geometry to be determined by means of photogrammetry. The existing laser device is placed on a mobile system that can be moved manually along the longitudinal direction of the channel and electronically along the transversal direction (4). The software that registers the data is programmed to obtain a raster from the surface of the model by means of a sequence of profiles.

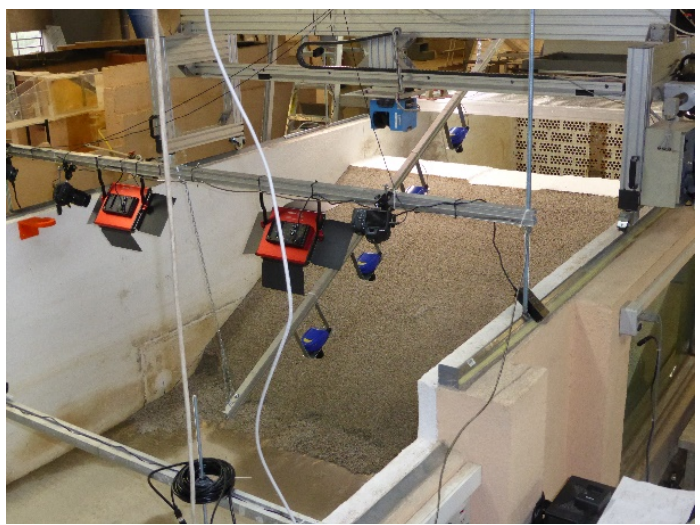

Figure 5. Photo taken from downstream showing the laser profiler (blue at the top of the image), level sensors LS 3,

LS_4, LS_5, and LS_6 (dark blue) and two of the cameras used of the photogrammetry during Test\#1.

The arrangement used in for the initial tests was designed to make one single profile at the transversal section (i.e. the section coincident with the axis of the lowered crest) during the whole duration of the test. The recording of each profile takes approximately 5-6 seconds. In addition to this, a recording of the entire test section surface is undertaken before and after each test - both states without water flow.

The photogrammetry setup consists of a series of 6 cameras (CAM1 to CAM6) located above the flume which obtain stereoscopic pairs of photos suitable for analysis to determine the external surface of the test section (5).

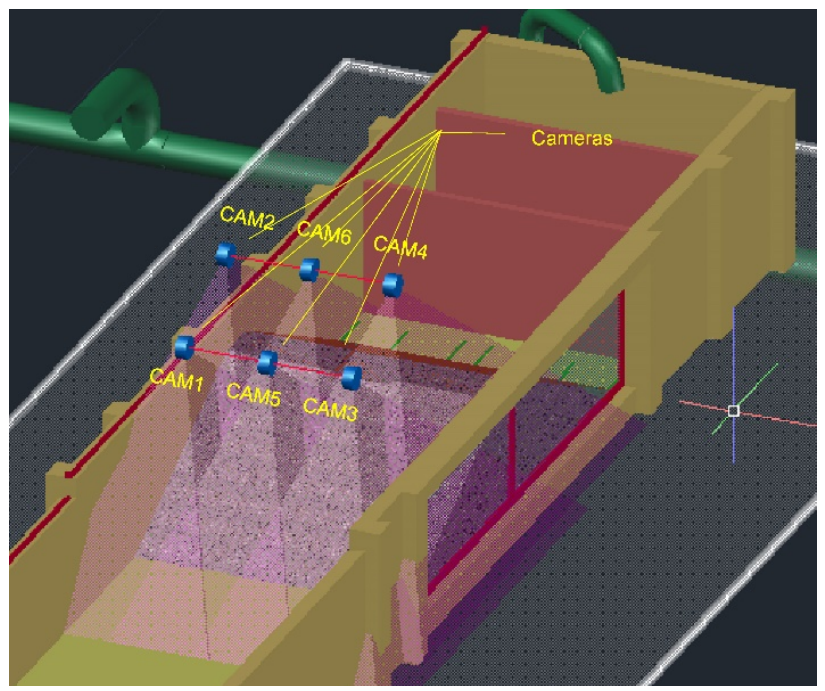

Figure 6. Location of cameras supporting photogrammetric analyses.

Tests are also video recorded and streamed online to allow the international research team to monitor progress in real time. A system of $4 \mathrm{HD}$ webcams is used, positioned as follows (6):

- WEBCAM 1. Front view from downstream.

- $W E B C A M-2$. Side view from the inspection window.

- WEBCAM_3. Plan view taken above the crest of the levee.

- WEBCAM_4. Front view of the panel of the piezometric measurements.

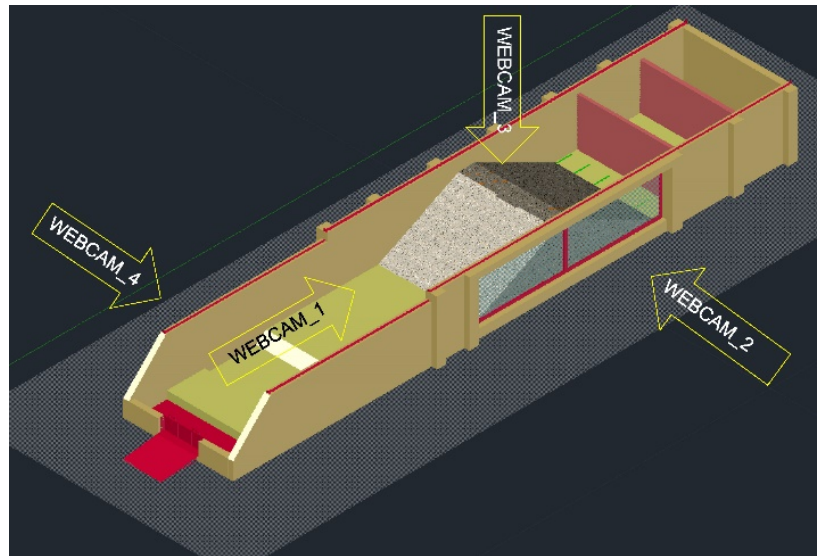

Figure 7. Location of webcams

\subsection{Initial tests}

At the time of writing, only Test\#1 it has been completed, and Test\#2 is under preparation, hence only results of Test\#1 are presented here. The main characteristics of the levee profile (Figure 8) are as follows:

- $\quad$ Material, homogeneous gravel 0-4mm (Table 1). 
- $\quad$ Crest height, $1.00 \mathrm{~m}$.

- $\quad$ Slope 2H:1V (both upstream and downstream).

- Upstream sealing with thin surface of mortar as a binder layer for the external cement grout.

- Volume of granular material $5.90 \mathrm{~m}^{3}$

- Crest length, $2.46 \mathrm{~m}$ (total width of the test channel).

- $\quad$ Crest width, $0.40 \mathrm{~m}$.

- $\quad$ Notch length, $0.50 \mathrm{~m}$ (Transverse slopes of 1H:1V till dam crest).

- Notch height, $0.015 \mathrm{~m}$ in the central $0.50 \mathrm{~m}$. Transverse slopes of $1 \mathrm{H}: 1 \mathrm{~V}$.

- Height of the notch, $0.985 \mathrm{~m}$.

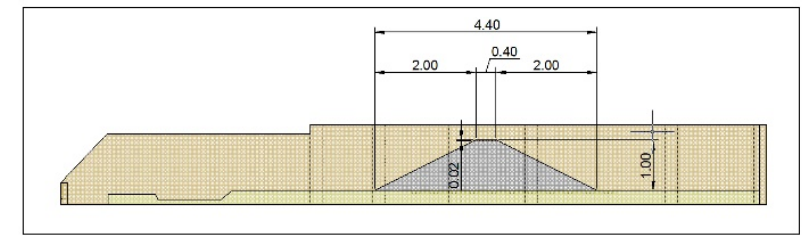

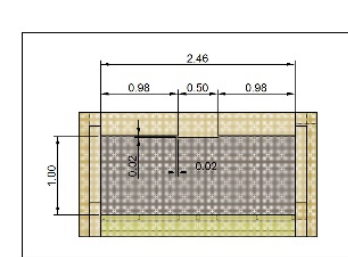

Upstream view

Figure 8. Dimensions of the levee prepared for Test\#1

\begin{tabular}{|c|c|}
\hline \multicolumn{2}{|c|}{ Grading (UPM) } \\
\hline Size (mm) & $\begin{array}{c}\text { Material Passing } \\
(\mathbf{\%})\end{array}$ \\
\hline 10 & 100.00 \\
\hline 6.3 & 99.86 \\
\hline 5 & 99.62 \\
\hline 3.15 & 50.00 \\
\hline 2 & 19.11 \\
\hline 1.47 & 10.00 \\
\hline 1.25 & 6.16 \\
\hline 1.01 & 5.00 \\
\hline 0.63 & 3.15 \\
\hline 0.4 & 2.46 \\
\hline 0.16 & 1.77 \\
\hline 0.08 & 1.41 \\
\hline
\end{tabular}

Table 1. Grading curves obtained of Gravel $0-4 \mathrm{~mm}$

The overflow discharge used during test $\# 1$ are shown in Table 2.

\begin{tabular}{|c|c|c|c|}
\hline $\begin{array}{c}\text { Time } \\
(\mathrm{hh}: \mathrm{mm}: \mathrm{ss})\end{array}$ & $\begin{array}{c}\text { Inflow } \\
\left(\mathrm{m}^{3} \mathrm{~s}^{-1}\right)\end{array}$ & $\begin{array}{c}\text { Reservoir } \\
\text { Level } \\
(\mathrm{m})\end{array}$ & Comments \\
\hline $00: 00: 00$ & $0.00 \mathrm{E}+00$ & & $\begin{array}{c}\text { Filling process } \\
(\mathrm{Q}=6.00 \mathrm{l} / \mathrm{s})\end{array}$ \\
\hline $00: 10: 39$ & $6.00 \mathrm{E}-03$ & $\begin{array}{c}\text { Filling stop }(\mathrm{Q}= \\
0.00 \mathrm{l} / \mathrm{s})\end{array}$ \\
\hline $00: 37: 41$ & $0.00 \mathrm{E}+00$ & 1.0073 & \\
\hline $00: 53: 27$ & $1.61 \mathrm{E}-03$ & 1.0104 & \\
\hline $01: 34: 57$ & $2.14 \mathrm{E}-03$ & 1.0137 & \\
\hline $03: 10: 49$ & $3.35 \mathrm{E}-03$ & 1.0149 & \\
\hline $04: 48: 54$ & $4.09 \mathrm{E}-03$ & 1.0164 & \\
\hline $05: 17: 38$ & $5.08 \mathrm{E}-03$ & 1.0174 & \\
\hline $05: 38: 28$ & $6.00 \mathrm{E}-03$ & 1.0179 & \\
\hline $06: 07: 30$ & $7.06 \mathrm{E}-03$ & 0.8836 & \\
\hline $06: 26: 32$ & $8.07 \mathrm{E}-03$ & \multicolumn{2}{|l}{} \\
\hline
\end{tabular}

Table 2. Inflow conditions for Test\#1

The levee test section was constructed manually, with material placed directly on the bottom of the flume, and construction following the profile guidelines drawn on the sidewalls of the flume (Figure 9). During placement of the material there was no compaction or moisture control for this initial test. For future tests, the construction process will vary according to the grading of materials.

To form the central notch, a wooden template was used. Finally, manual tools and scaffolding was used to allow the placement of the different materials to apply the sealing layer on the levee crest and upstream face.

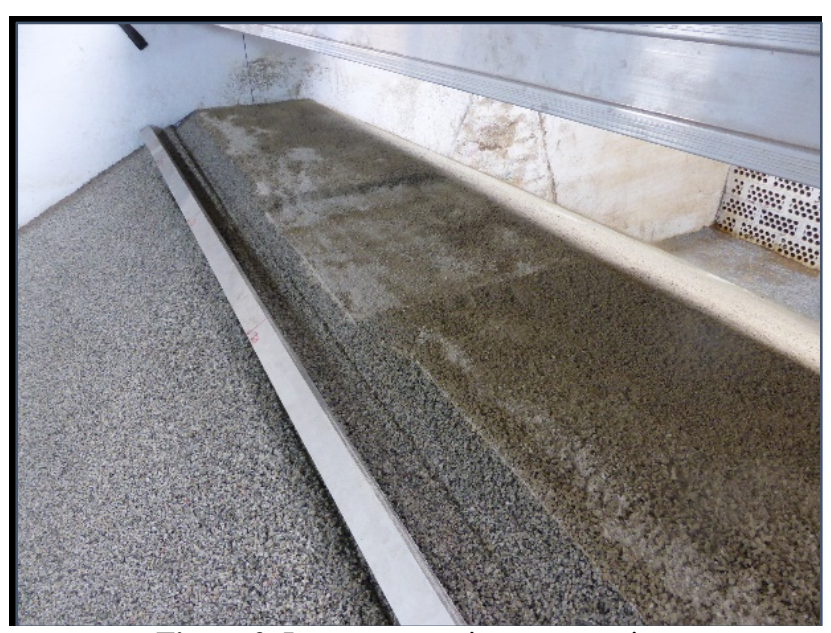

Figure 9. Levee test section construction

Conclusions obtained from Test\#1 can be summarized as follows:

(i) This test represents an example of highly permeable, coarse material where the overflow transitions into a combination of seepage throughflow and skimming flow on the downstream face

(ii) As the material is clean, with a very low content of fines, particle dragging was the main failure mechanism, with the presence of slumping at the downstream toe, and lateral mass sliding when 
the slopes of the erosion channels became unstable (Figures 10 and 11).

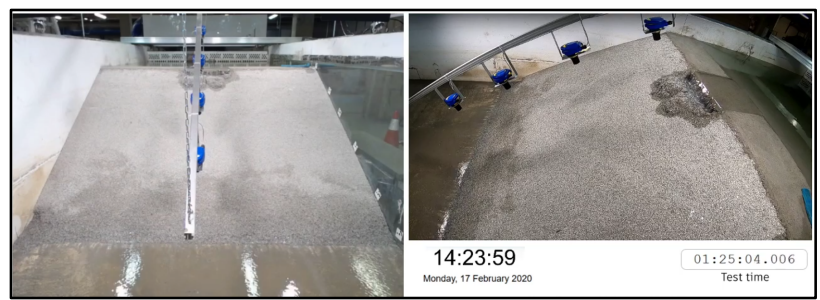

Figure 10. End of Step\#3 (overflow discharge 1.61E-03 $\mathrm{m}^{3} \mathrm{~s}^{-1}$ )

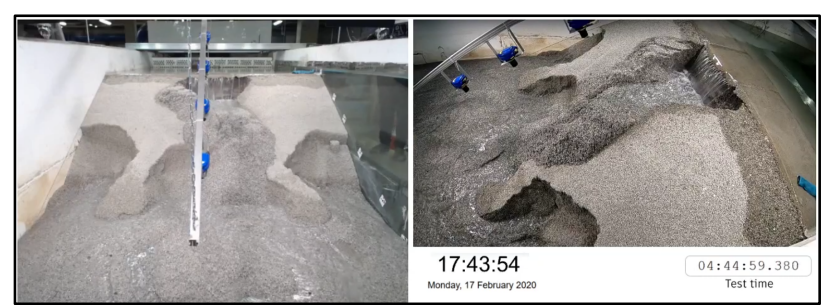

Figure 11. End of Step\#5 (overflow discharge $3.35 \mathrm{E}-03 \mathrm{~m}^{3} \mathrm{~s}^{-1}$ )

Test\#1 was intended to be a 'upper bound' case to check the presence (or absence) of surface erosion processes in coarser materials with a low content of fines. The higher-than-expected resistance of the mortar sealing layer on the upstream face and crest was an issue which affected the failure processes, especially in the final phases, where plunging flow was initially created by resistance of the crest mortar layer to a more progressive failure pattern, and then subsequently a significant surge in flow when this protective layer was progressively undercut and eventually failed catastrophically.

\section{Progress with the field test programme}

In parallel with the laboratory test programme work has progressed on the design of a larger scale field test facility.

\subsection{Objectives for the field test facility}

The facility is intended to allow for a programme of larger scale tests (levee section height up to $2.5 \mathrm{~m}$ ) that would build from and complement the laboratory test programme. It was considered prudent to create the facility to test larger / prototype scale levee sections because of the complex mixture of surface and internal flow processes that occur during breach and the need to limit scale effects in their analysis.

\subsection{Location and design constraints}

A test site was located in the Ebro River Catchment Authority area near Laverné in Spain. The area comprises an irrigation water supply canal, concrete flow transfer channel, open channel section and a large downstream water storage reservoir. The site fits the requirements for a potential field test site in that:

- The Ebro Catchment Authority are happy for the research facility to be constructed at this location.

- The irrigation canal and transfer channel provide a reliable source of flow for tests - up to $\sim 10 \mathrm{~m}^{3} / \mathrm{s}$.

- The irrigation system and desert location means that there is little or no additional impact on the environment.

- A second transfer channel allows for the passage of water from the irrigation canal to the storage reservoir without use of the proposed test site.

- A test site can be constructed such that irrigation water flows through / over the test site when not in research use.

See Figures 12, 13 and 14.

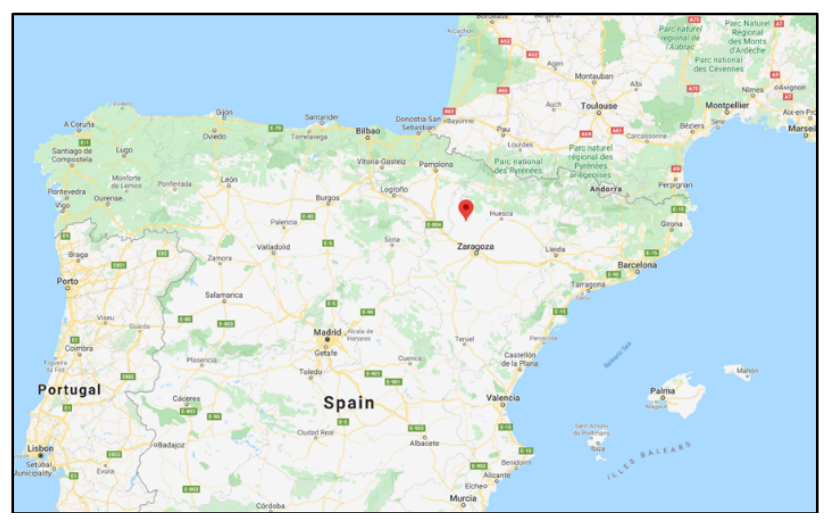

Figure 12. Laverné field test site location (Spain) (Google Maps 2020)

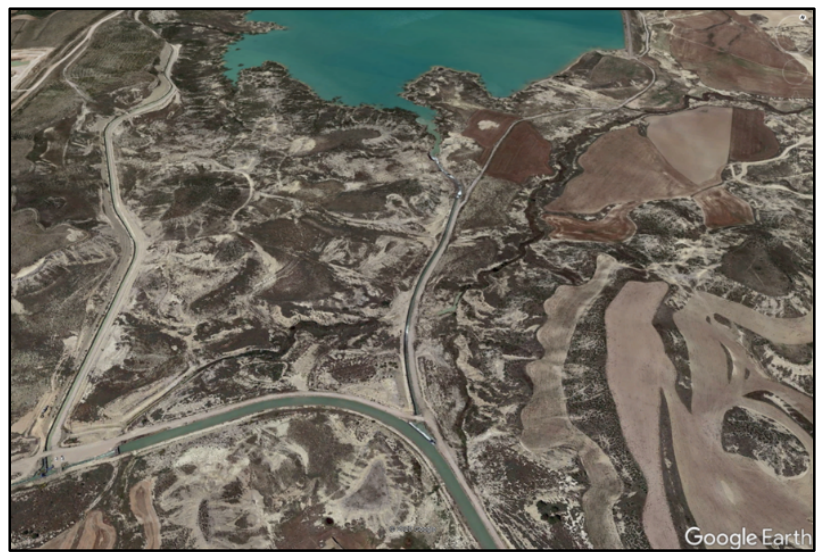

Figure 13. Laverné field test site: Irrigation canal (foreground); transfer channel (centre); open channel (upper centre); storage reservoir (upper). (Google Earth 2020) 


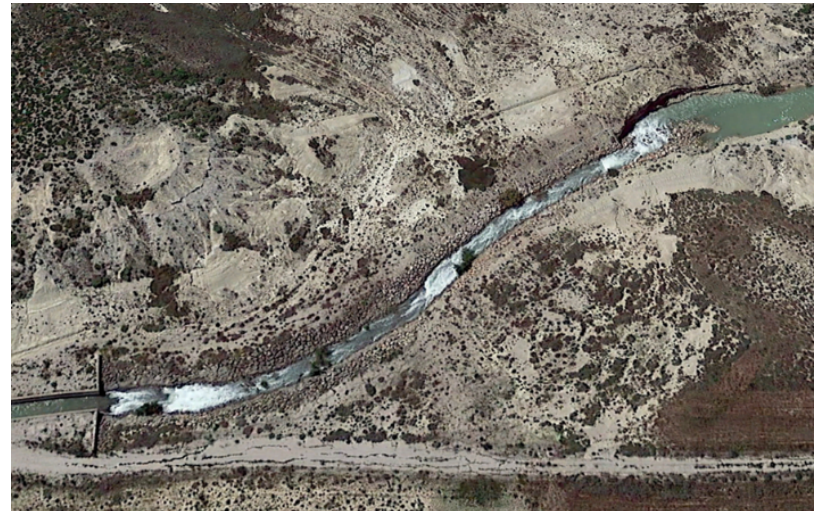

Figure 14. Laverné field test site: Open channel section between transfer channel and storage reservoir (Google Earth 2020).

The following steps were then undertaken in order to progressively confirm suitability, functionality and cost of the field test site:

- $\quad$ Site topographic survey

- $\quad$ Site geological survey

- Conceptual design of the field test site

- Preliminary design / budget estimate of the field test site

\subsection{Optimal design - balancing constraints, costs and future potential}

The topographic survey covered from the irrigation canal, along the transfer channel and subsequent open channel to the upper reaches of the storage reservoir. This provided enough data to allow consideration of test site locations anywhere from within the transfer channel to the edge of the storage reservoir.

The geological survey confirmed acceptability of the site for a test facility, albeit recommending that any use of the open channel flow area should be sealed and protected to avoid any erosion and seepage losses.

Conceptual design of the test facility then looked at different options, taking into consideration:

- Location of the facility - ranging from within the transfer channel to any location within the open channel between the transfer channel and the reservoir.

- Size of the facility - whether constrained within the transfer channel or unrestricted within the open channel.

- Elevation of the facility - particularly in relation to the invert of the transfer channel and any potential water storage capacity upstream of the facility.

- $\quad$ Ease of construction and costs.

The ability to store water upstream of the test facility is an important issue to be considered since as breach formation through a levee section develops, the flow can rapidly increase. If research into breach widening as well as breach formation is required (...it is...) then having a significant storage capacity upstream helps to offset the need for a large capacity and very responsive flow supply. Whilst from an aerial perspective it may be considered best to locate the test facility closer to the lake, and to use the upstream open channel for water storage, the bed gradients are quite steep and only very limited storage could be obtained without building an expensive elevated structure along with bunds to contain the approach flow within the channel area. The effect of steep gradient on potential storage volume is clearly shown in Figure 15.

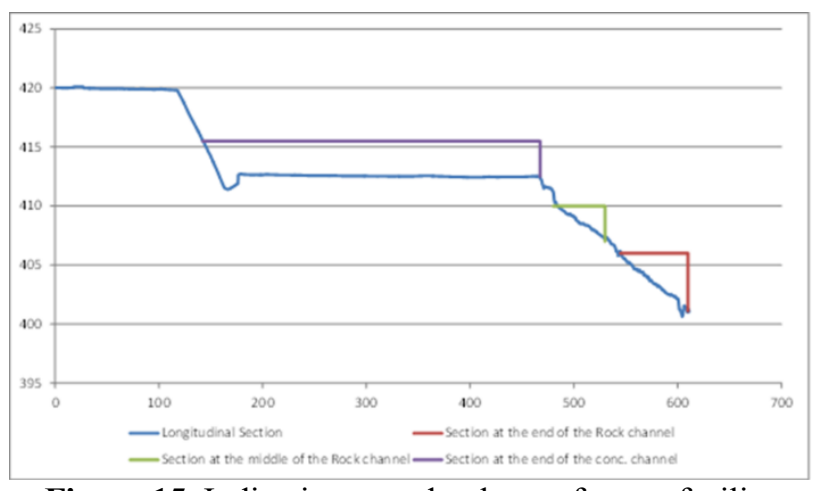

Figure 15. Indicative stored volumes for test facility locations

Subsequently, analyses were focussed on a potential facility located within $50 \mathrm{~m}$ of the transfer channel, or within the transfer channel itself. Breach simulations were undertaken using the EMBREA breach prediction model (Morris (2011); Morris \& Hassan (2018)) to see how different facility locations, elevations and supply flows affected the potential for breach research.

Initial simulations looked at how a test facility might perform within the transfer channel (TC). The TC is a rectangular concrete channel, $4 \mathrm{~m}$ wide and $3.5 \mathrm{~m}$ deep providing a ready made flume. Discharge from the main irrigation canal can provide flows up to $10 \mathrm{~m}^{3} / \mathrm{s}$. Apart from the issues of access, blockage etc., breach analyses using EMBREA and a steady supply flow of $1 \mathrm{~m}^{3} / \mathrm{s}$ showed that for a $3 \mathrm{~m}$ high test section, erosion during breach formation would likely reach the TC sides before the base. Even allowing for a smaller test section and uncertainties in breach modelling, the conclusion remains the same; using the TC would inhibit the scope of breach erosion testing, restricting the focus just to initial erosion during breach formation and certainly no or very little breach widening (See Figure 16 showing breach modelling results). 


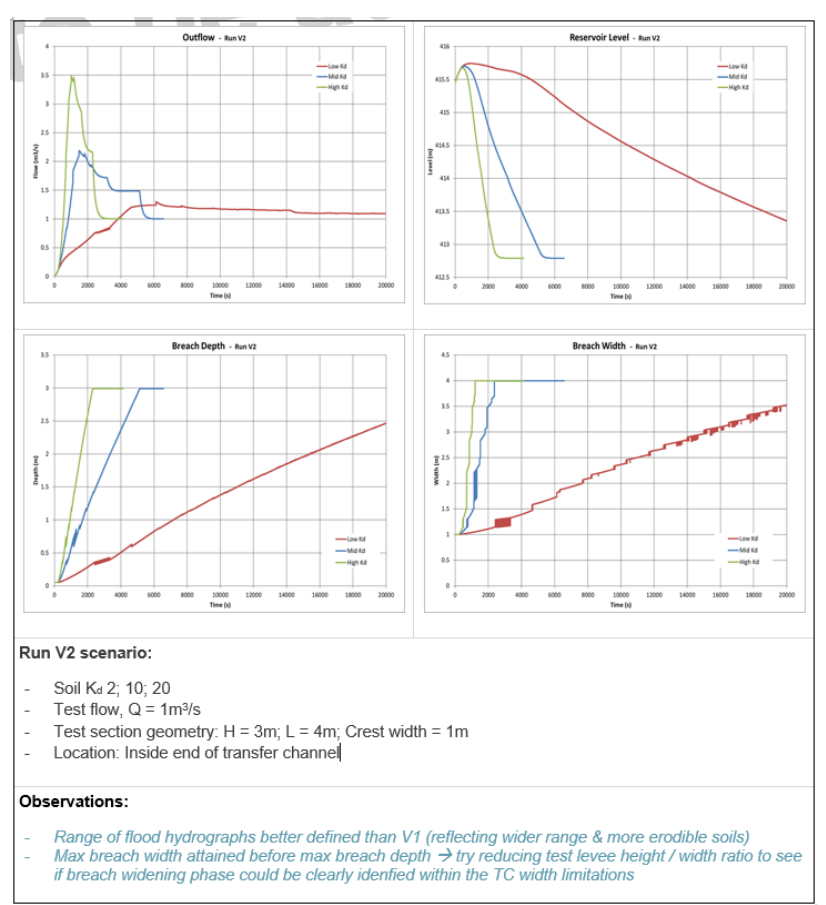

Figure 16. Breach modelling results for V2 scenario (test facility located within the transfer channel)

Similar breach analyses were then undertaken assuming different test facility locations, size and elevations. This process allowed the following conclusions to be drawn for the preliminary design:

(i) Construction within the transfer channel restricts the range of testing and will prevent any analysis of breach widening processes. Hence the test location should be downstream within the open channel.

(ii) A location close to the transfer channel $(30 \mathrm{~m}$ downstream from outlet) is preferable to further along the open channel due to the steepness of the open channel. A location closer to the transfer channel allows use of water storage within the transfer channel and reduces the amount of earthworks.

(iii) An invert level at the same level as the transfer channel is beneficial in using the storage capacity of the transfer channel to drive tests

a. Should a lower invert be required, it may reduce by up to $1 \mathrm{~m}$ but not further. This still allows for some use of storage in the transfer channel. The best level is to match the transfer channel invert.

(iv) A test section of $2 \mathrm{~m}$ high by $8 \mathrm{~m}$ wide (minimum) allows for large scale testing, including the development of breach widening processes after breach formation has completed.

(v) A steady base flow up to $1 \mathrm{~m}^{3} / \mathrm{s}$ is sufficient to drive the test cases without the need for complex flow bypass controls. (vi) Flows up to $10 \mathrm{~m}^{3} / \mathrm{s}$ can be provided and used to simulate greater upstream storage volumes. Assuming control from the irrigation canal would be difficult and slow (delayed) a flow bypass system would be needed to control flows locally at the test site. This can be manually controlled in steps rather than automated.

b. A discussion is needed as to whether the costs and complexity of bypass-controlled flows is worth the gain in research data quality. A simple $1 \mathrm{~m}^{3} / \mathrm{s}$ base flow (with simple local flow bypass) may be simpler and sufficient.

Analysis of dynamic flow behaviour compared to the EMBREA flat pond modelling approach has been undertaken and the differences appear to be small (HR Wallingford, 2021)

\subsection{Preliminary facility design and cost estimation}

Following completion of the conceptual design, plans were drawn up for the test facility construction. These included facility specific details such as:

- Test flow control system (flow bypass control to allow flow adjustment during tests)

- Facility bypass system (flow bypass under facility when tests are not being performed)

- Instrumentation (for access and monitoring during tests)

- $\quad$ Power, water, access and support facilities etc.

Figures 17 and 18 shows a cross section through, and plan of, the proposed test facility respectively. This shows a test bed which is $8 \mathrm{~m}$ wide, but with sloping sides. The chosen invert level for the test facility matches that of the transfer channel in order to maximise water storage upstream. With the facility located $30 \mathrm{~m}$ downstream from the end of the transfer channel, small bunds are required either side of the open channel to retain the flow. These are $3 \mathrm{~m}$ high at the facility test section, allowing for levee sections $2.5 \mathrm{~m}$ high to be tested (with a freeboard of $0.5 \mathrm{~m}$ ).

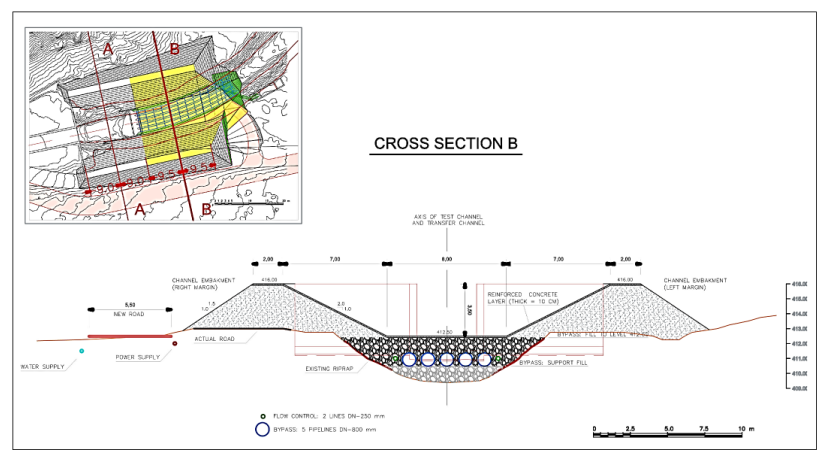

Figure 17. Cross section through planned test facility 


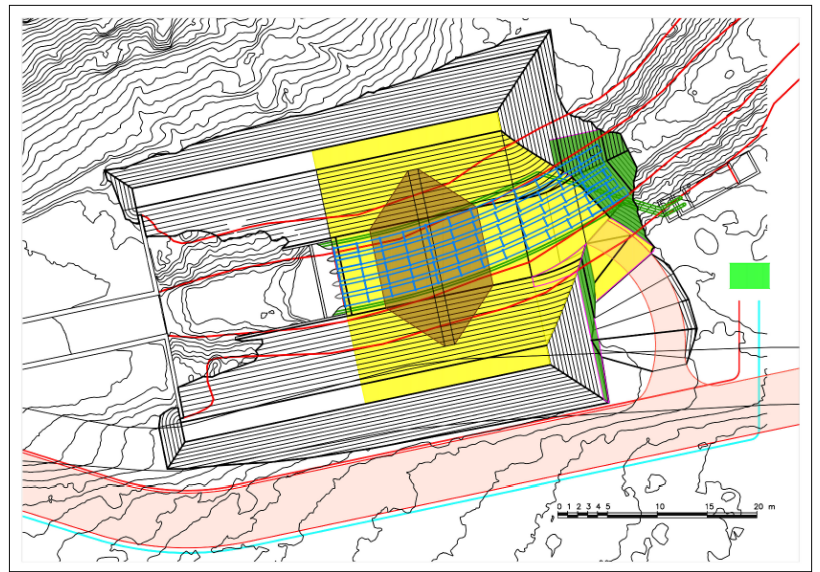

Figure 18. Plan of the proposed test facility

\subsection{Instrumentation}

Deciding upon the best form of instrumentation has been a difficult decision. The challenge for monitoring the dynamic evolution of breach through a test section, whether in the laboratory or the field, is how to monitor a rapidly changing soil surface through turbulent and often murky water. Despite various researchers reporting on the use of green laser systems to shoot through water, it appears that the reliability of such systems to operate through murky and / or turbulent conditions is questionable. The cost of such systems are also substantial.

The final decision was to undertake monitoring using photogrammetry combined with water level, flow and point measurements. The instrumentation will comprise:

- Electronic flow measurement unit in upstream transfer channel (total flow into the facility)

- Electronic water level gauges up and downstream of the test facility

- Test facility flow bypass control - up to $2 \mathrm{~m}^{3} / \mathrm{s}$ via valve control with weir measurement of flow from bypass flow chamber

- Fixed instrument frame across the channel up and downstream of the test facility for positioning of photogrammetry and video cameras (left, right \& centre)

- Moveable bridge across the test facility for photo and video cameras as well as manual depth measurement

- Further downstream of the test facility, a small retention dam to trap eroded sediment for subsequent removal

- Downstream of the retention dam, a small flow measurement weir (with water level recorders) to measure total flow out of the facility.

\section{Next steps}

Whilst the COVID-19 pandemic has slowed the schedule and affected funding for this project, the original programme of parallel laboratory and field tests to investigate and confirm both macro and micro breach formation processes remains the goal. During 2021 the programme of laboratory tests at UPM will continue, with some additional tests undertaken at CNR laboratories in Lyon also foreseen. Efforts to align the programme of tests with erosion tests undertaken in the US (ERDC, USBR) during 2018-2019 will also be made to add value to both US and European programmes.

Tendering for construction of the field test facility will take place as soon as the finance is confirmed by EDF. This is anticipated for Spring / Summer 2021, allowing facility construction in the latter half of 2021, and subsequently to initiate large scale tests at the facility from 2022. Since the cost per large scale test is estimated to be $\sim 10$ times the cost per laboratory test, these large-scale tests will only proceed once key erosion behaviour has been established at the smaller scale; the purpose of the larger scale tests is to confirm that these key processes are seen to behave in a similar manner at prototype scale.

Ultimately, the knowledge gained from both the laboratory and field test programmes will be used to improve and validate breach prediction models for industry application.

\section{References}

1. Bureau of Reclamation (2017). Evaluation of Numerical Models for Simulating Embankment Dam Erosion and Breach Processes. Dam Safety Technology Development Program, Report DSO2017-02.

2. Hanson, G. J., Robinson, K. M. \& Cook, K. R. (2001). Prediction of headcut migration using a deterministic approach. Transactions of the American Society of Agricultural Engineers, Vol. 44 (No. 3), pp 525-531.

3. HR Wallingford (2021). Coarse Grained Erosion Breach Research. HR Wallingford Report MCM8266RT-02.

4. Morris, M.W. (2011). Breaching of earth embankments and dams. PhD. The Open University, England.

5. Morris, M. W. \& Hassan, M.A.A.M. (2018). The effect of material zones and layers on breach growth and prediction. $3^{\text {rd }}$ International conference on protection against overtopping, 6- $8^{\text {th }}$ June 2018, UK.

6. Morris, M. W., Hanson, G. J. \& Hassan, M. A. A. M. (2008). Improving the accuracy of breach modelling: why are we not progressing faster? Journal of Flood Risk Management, Vol. 1 (No. 4), pp pp. 150-161. 